\title{
Could Intelligent Computers Postulate Their Own Evolution Theory Which Would Be More Plausible than that of the Humans?
}

\author{
Abd Al-Roof Higazi ${ }^{1,2}$ \\ ${ }^{1}$ Department of Clinical Biochemistry, Hadassah-Hebrew University, Jerusalem, Israel \\ ${ }^{2}$ Departments of Pathology and Laboratory Medicine, Perelman-University of Pennsylvania, School of Medicine, Philadelphia, \\ USA \\ Email:abdh@ekmd.huji.ac.il
}

How to cite this paper: Higazi, A. (2018). Could Intelligent Computers Postulate Their Own Evolution Theory Which Would Be More Plausible than that of the Humans? Open Journal of Philosophy, 8, 23-27. https://doi.org/10.4236/ojpp.2018.81003

Received: November 24, 2017

Accepted: February 10, 2018

Published: February 13, 2018

Copyright $\odot 2018$ by author and Scientific Research Publishing Inc. This work is licensed under the Creative Commons Attribution International License (CC BY 4.0).

http://creativecommons.org/licenses/by/4.0/

(c) (i) Open Access

\begin{abstract}
How did life come into existence on Earth? Although many scientific theories and hypotheses have been drawn, we have not yet been able to provide a detailed answer to this fundamental question. What if intelligent computers would someday be in a condition to postulate their own evolution theory which would explain how they came into the world, how would this theory look like? And how would it stand in comparison to the humans' theory? Let us suppose that a thousand years from now, intelligent and self-aware computers who, for any reason whatsoever, had lost all contacts with humans, and had continued to self-develop and improve by themselves, slowly began to wonder about how they came into the world? These intelligent computers may eventually develop a coherent theory of evolution, which would seemingly explain their existence. How would their theory stand in comparison to our theory of evolution? Would it be less comprehensive or viable? Taking into consideration the inorganic nature of computers, their relative simplicity compared to the human body, and the closeness of their components to the surrounding inorganic environment, it would not be a surprise if their theory would be more plausible than that of the humans. So, what would this signify and mean to our scientific theories in general?
\end{abstract}

\section{Keywords}

Evolution Theory, Inorganic Life, Erroneous Theories

\section{Introduction}

In 1997, a computer with artificial intelligence beat the (human) world chess 
champion for the first time. The IBM supercomputer was named Deep Blue. Many chess masters blamed the world champion's defeat on a single move made by the computer. Fifteen years later, one of the computer's designers argued that the winning move came from a bug in the software. He argued that Deep Blue "invented" a new move through a spontaneous malfunction. The machine was backed into a corner, unable to calculate any advantageous move; so Deep Blue picked one at random and invented a completely new move. That move defeated the chess world champion.

This theory of Deep Blue's victory is fascinating. Computer software often contains bugs and mistakes. As was witnessed, these glitches can sometimes coincidentally improve the computer's function. It's a process that mirrors the theory of human evolution: mistakes in the DNA lead to our evolution. Humans managed to evolve through mistakes; could computers also evolve in a similar way?

Another potential path to computer evolution is through self-improvement. Humans have only recently begun to develop this fascinating technology which should, in the near future, allow us to improve our genes and our DNA in potentially unlimited ways. Intelligent computers which are programmed to learn and to self-improve could evolve at a fast and effective rate. When compared to the vast complexity of the human body, which limits our capacity to intervene in our genome, the relatively simple structure of the computers would permit a much higher rate of self-evolution.

All things considered, it is theatrically possible that one day computers will achieve a comparable level of intelligence (in certain aspects) to humans, and perhaps even surpass us. Thereby, these intelligent computers may, as a result of prolonged isolation or any other reason, disregard their history with humans and begin to wonder about how they came into the world.

In case these intelligent computers develop a theory of evolution which explains their existence, how would their theory look like? And how would it stand in comparison to our theory of evolution?

\section{Why Would Computers Come up with an Evolution Theory?}

Let us suppose that computers with Artificial Intelligence (AI) were developed by humans and were designed to learn and to self-improve, and that for unknown reasons, these intelligent computers had lost contact with humans. In spite of this, the computers continued to self-develop and evolve.

In the distant future, extensive improvements to the computers' software and hardware have taken place as a result of built-in programs which are responsible for learning, development and improvement and which also get updated by the computers themselves. Bugs and glitches which were examined by the computers and were found to be beneficial were selected and used to further their improvement. 
All of the changes and improvements that took place within the computers were recorded, and computers were aware of the constant changes they were undergoing and of the progress they were making.

As intelligent beings, and as in the case of humans, the computers would eventually begin to wonder and to ask themselves "where did we come from?"

Taking into consideration the availability of older generations of computers which have inferior software, hardware and calculation capacities, and the steady improvement which occurred up until their current time, it is logical from their point of view to think about a process of gradual evolution.

\section{How Would Their Evolution Theory Look Like?}

Based on the elements present in their predecessors (older models), how they construct themselves and on the components they use for such purposes, including simple elements like metals, computers may assume that they slowly evolved autonomously from in-organic materials present in their environment.

Indeed, a computer's evolution hypothesis can be rational and supported by valid archeological findings, scientific arguments and facts. Even more, compared to that of the humans, the computer's theory may be more coherent and scientifically solid.

The reasons behind the strength of the computers' theory in comparison to the humans', among others, are: First, the computers are built from inorganic materials that are more prevalent and available in nature than organic components; computer's components are much closer to the surrounding inorganic environment. In contrast to computers, humans' bodies are composed of complex and precisely designed organic components like amino and nucleonic acids (Higazi, 2017: Supp. 2) and proteins (Higazi, 2017: Supp. 3) that were developed from inorganic elements, in a process that is not entirely clear (Higazi, 2017: Supp. 2-3). 2nd, a computer's structure is many times simpler than that of a human. Therefore, it is easier to accept their spontaneous development theory. 3rd, "archaeological" evidence which could be discovered by computers, could very nicely support the concept of gradual development of computers, in contrast to the humans' theory where there are numerous missing central "links". 4th, computers can prove their theory in a laboratory by showing the feasibility of almost all of the critical stages of their development. Even more, computers can build complex computers from simple inorganic elements, but humans cannot build humans or even a single living cell.

Another fact that may support the computers' evolution theory is the surrounding universe. Our universe is inorganic and behaves based on well-defined physical and chemical rules, which in turn provide the precise and complex conditions (such as gravity, temperature, climate, etc.) which permit organic and inorganic "lives" to exist. Consequently, it is not irrational to reach the conclusion that our solar system, galaxy and the whole universe function as one big computer which developed in a spontaneous manner. So why cannot "small" 
computers like the ones we're describing go through an analogous process of development.

All things considered, any outside observer who would be asked to compare the humans' and computers' hypotheses, would favor the computers' one.

\section{So, What Does This Mean?}

There is no doubt that the computers are asking the right questions, and have valid findings and arguments but ultimately reach false answers and conclusions.

\section{What Causes This to Occur?}

The reason behind the erroneous conclusions of the computers' evolution theory is the unproven assumptions which it is based on. The major one, is the assumption about the theoretical possibility of a spontaneous formation of the first functional unit; the first computer able to have any simple function and/or to reproduce itself.

Any evolution theory would assume that several basic elements present in a certain space would have randomly organized in the right way and produced the first functional unit(s). We know that this never happened with computers, and that humans put together these "relatively simple" elements needed to assemble this first functional unit.

The reason their hypothesis is more accurate than that of the humans is the fact that there are even more unproven assumptions in the humans' theory. For example, the humans and the computers share the same assumption that is the accidental assembly of their first functional unit, which in the case of humans, had to be much more complex, and therefore, having a lower chance of randomly occurring. Furthermore and in contrast to computers, humans do not have any idea regarding how their first functional unit would have looked like.

In addition, the humans' theory is based on some unproven assumptions that do not exist in the computers' theory. This includes, among others, the development of energy sources for the first functional units. The computers' energy-generation functionality is very simple. While they can use electric energy easily generated by the sun with the use of a naturally available photo electric cell such as a Perovskite (Higazi, 2017: Supp. 1), the use of sun light to generate energy in the case of organic life is much more complex. Photosynthesis by itself is a sophisticated minimally-functioning-unit where all of its parts have to be generated and assembled at the same time and it is still not very clear how it originated (Higazi, 2017: Supp. 5-6).

\section{So, What Are the Conclusions?}

The experience of the computers emphasizes the age old contention, which sometimes can be forgotten, that any scientific theory which is based on unproven assumptions may lead to wrong conclusions and mask the truth. Therefore, we should always be aware that not everything that is theoretically acceptable can be true. 


\section{References}

Higazi, A. A. (2017). Science Worship and Evolution's Secrets. Supplement 1, Computers Source of Energy. Azur: Zameret Books.

Higazi, A. A. (2017). Science Worship and Evolution's Secrets. Supplement 2, Basic Components of Living Cells. Azur: Zameret Books.

Higazi, A. A. (2017). Science Worship and Evolution's Secrets. Supplement 3, Proteins. Azur: Zameret Books.

Higazi, A. A. (2017). Science Worship and Evolution's Secrets. Supplement 5, Organic Energy. Azur: Zameret Books.

Higazi, A. A. (2017). Science Worship and Evolution's Secrets. Supplement 6, Evolution of Enzymes. Azur: Zameret Books. 